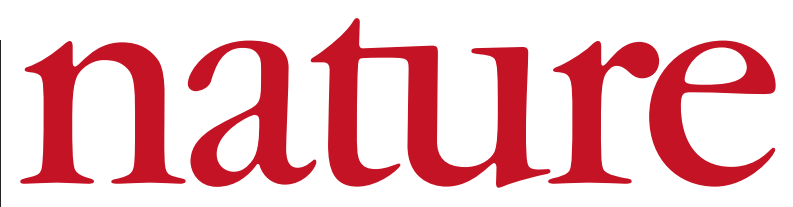

11 October 2001 Volume 413 Issue no 6856

\title{
'Big science' and public trust
}

Viewing the budget crisis enveloping Europe's leading particle-accelerator lab, politicians may conclude that high-energy physicists cannot be trusted to manage billions of dollars of public money. This perception must be reversed - and fast.

$\mathrm{T}$ he first collision at the Large Hadron Collider (LHC) has occurred, somewhat earlier than expected. But it is not highspeed protons that have met head-on. Instead, projected cost overruns of several hundred million dollars have careered into the proud record held by CERN, the European particle physics laboratory near Geneva, for having previously delivered such projects on time and on budget.

Most worrying is the suggestion that poor financial management and inadequate accounting procedures are at least partly to blame (see page 557). In their defence, CERN's managers say that the true cost of developing and installing the required magnets and other technology could not have been fully predicted at the outset. In many respects, the laboratory was taking a step into the unknown, they argue. CERN also had no choice but to start working on the LHC without the sort of contingency funds that are often built into projects of this size - its member states were never prepared to stump up the necessary cash.

But CERN has so far made no attempt to absorb the cost of developing the prototype magnets for the LHC into the lab's central budget, as was intended. And while its director-general, Luciano Maiani, argues that it has only recently been possible to carry out a meaningful cost review, to have explicitly denied rumours of significant cash problems as recently as June is inexcusable.

Worse still, the lab then issued a self-congratulatory press release, entitled " 1754 days to the LHC and counting!". No wonder representatives from CERN's member states feel aggrieved. CERN's decision to set up an 'office for spending control' is a welcome move. But it is a belated one, and amounts to a tacit admission of faults in the financial management of the LHC project.

Many observers will question why such a prestigious horse was allowed to bolt before CERN installed, let alone closed, its stable door. This office needs to quickly demonstrate its ability to get the LHC project back on track, because more than CERN's reputation is riding on this particular horse.

The international high-energy physics community is now beginning to talk up its next big project — an enormous linear electron-positron collider. One reading of the current situation is that CERN's current troubles make it more likely that the next machine will be built in the United States. Certainly, after the débâcle of the Superconducting Supercollider, cancelled by the US Congress in 1993 amid spiralling costs, some US physicists - although not those who are heavily engaged at CERN - may take a grim pleasure in learning that their European counterparts are not immune to budget problems.

Given a gloomy economic climate, however, CERN's woes may convince the world's politicians that they have better things to do with public money than to give it to high-energy physicists. The scientific case for the next-generation linear collider may be strong, but politicians will need much convincing to commit money to it.

If the political fallout from the LHC crisis is not to lead to a global reluctance to fund such projects, CERN must first acknowledge that it has made mistakes, and then demonstrate that it has learnt from them.

\section{Bangladesh's poisoned wells}

\section{Scientists and government officials bear collective responsibility for an unfolding tragedy.}

$\mathrm{T}$ he people of Bangladesh have endured flood, famine and disease. Now they must contend with a mass outbreak of arsenic poisoning that, according to one expert, makes the Chernobyl disaster "look like a Sunday-school picnic". The irony is that this catastrophe is the direct result of well-intentioned attempts to provide the nation with safe water for drinking and irrigation.

Up to 75 million Bangladeshis are at risk. A British court will soon be asked to decide whether one organization, the British Geological Survey, can be held accountable for its role in the crisis (see page 556). The case holds the prospect of hundreds - maybe thousands - of victims gaining compensation. But some experts fear that the threat of legal liability may in future deter Western hydrogeologists from working in the developing world.

That would compound the tragedy, because the expertise of Western scientists is still urgently needed. Wells will continue to be sunk across the Ganges delta, and without further research into the causes and extent of arsenic contamination, they may continue to draw from bodies of tainted groundwater.

Western hydrogeologists also have a moral obligation to the people of Bangladesh. Together with government officials and local scientific experts, they must accept collective responsibility for the long delay in recognizing the problem.

When the first wells were sunk in Bangladesh in the 1970s, nobody suspected that arsenic could contaminate groundwater in river-plain sediments. Reports of arsenic poisoning related to wells sunk into such deposits began to emerge from West Bengal, across the Indian border, in 1983. Yet the first major conference on arsenic poisoning in the region and subsequent attention in the international scientific literature did not follow for more than a decade.

Government officials in Bangladesh and West Bengal — keen not to shoulder the burden of yet another public-health crisis in full view of the international community — had a hand in this. Warnings from local public-health experts in the mid-1980s were ignored. But both Western scientists and their colleagues on the Indian subcontinent must ask themselves whether they could not have done more to ensure that news of this public-health disaster emerged more quickly.

By accepting some of the blame, the scientific community may make it easier for local officials to take their share of the responsibility — and allow everyone to work towards preventing further loss of life. 